\title{
O papel da mídia na construção da agenda governamental para o SUS no Rio de Janeiro
}

\section{The role played by mass media in constructing the governmental agenda on SUS in Rio de Janeiro \\ El papel de los medios de comunicación de masas en la construcción de la agenda del gobierno de Rio de Janeiro para el SUS}

\author{
Débora Castanheira ${ }^{1,2, a}$ \\ deboracastanheira1@gmail.com | https://orcid.org/o000-0001-6995-1259
}

Clara Faulhaber ${ }^{3, b}$

clarafaulhaber@gmail.com | https://orcid.org/0000-0001-8062-8030

Silvia Gerschman ${ }^{4, c}$

gerschman@ensp.fiocruz.br | https://orcid.org/0000-0001-5473-7567

\footnotetext{
${ }^{1}$ Fundação Oswaldo Cruz, Instituto de Comunicação e Informação Científica e Tecnológica em Saúde. Rio de Janeiro, RJ, Brasil.

2 Universidade Estadual do Rio de Janeiro, Instituto de Estudos Sociais e Políticos. Rio de Janeiro, RJ, Brasil.

${ }^{3}$ Universidade do Estado do Rio de Janeiro, Centro de Estudos Sociais. Rio de Janeiro, RJ, Brasil

${ }^{4}$ Fundação Oswaldo Cruz, Escola Nacional de Saúde Pública, Rio de Janeiro, RJ, Brasil.

a Doutorado em Ciência Política pela Universidade Estadual do Rio de Janeiro.

• Graduação em Ciências Sociais pela Pontifícia Universidade Católica do Rio de Janeiro.

c Doutorado em Ciências Sociais pela Universidade Estadual de Campinas.
}

\section{Resumo}

O objetivo deste artigo é analisar o papel da mídia na formulação da agenda governamental de saúde no estado do Rio de Janeiro. Foram coletadas notícias publicadas sobre o tema nos três jornais de maior circulação nesse estado entre 2003 e 2011. Reuniram-se 3.305 notícias, posteriormente agrupadas em oito categorias. A análise dos dados mostra que a mídia foi o principal ator do processo de mudança do modelo de gestão das unidades de saúde, ao enquadrar o tema de forma a favorecer uma visão negativa da prestação de serviços feita diretamente pela administração pública. Isso permitiu a formação de uma opinião pública favorável ao projeto de implantação de organizações sociais apresentado pelo governador Sérgio Cabral e seu secretário de Saúde, Sérgio Côrtes.

Palavras-chave: Gestão da saúde; Sistema Único de Saúde; Privatização; Meios de comunicação de massa; Organização social. 


\begin{abstract}
The purpose of this article is to analyze the role of mass media in creating health governmental agenda in the state of Rio de Janeiro. We collected news published on the subject in the three most circulated newspapers in that state from 2003 till 2011. We gathered 3.305 news and subsequently we grouped them into eight categories. The analysis of data shows that the media was the main actor in the process of changing the management model of the health units by framing the theme so that to favour a negative view on the provision of services directly by the public administration. This allowed the formation of a public opinion favorable to the project of implantation of OS - organizações sociais (social organizations, a specific kind of private association) presented by the governor Sérgio Cabral and his secretary of health, Sérgio Côrtes.
\end{abstract}

Keywords: Health management; Unified health system; Privatization; Mass media; social organization.

\title{
Resumen
}

El objetivo de este artículo es analizar el papel de los medios de comunicación de masas en la formulación de la agenda gubernamental de salud en estado de Río de Janeiro. Se recogieron noticias publicadas sobre el tema en los tres periódicos de mayor circulación en aquel estado entre 2003 y 2011. Se reunieron 3.305 noticias, posteriormente agrupadas en ocho categorías. El análisis de los datos muestra que los medios de comunicación de masas fueron el actor principal del proceso de cambio del modelo de gestión de las unidades de salud al encuadrar el tema favoreciendo una visión negativa de la prestación de servicios directamente por la administración pública. Esto permitió la formación de una opinión pública favorable al proyecto de implantación de OS - organizações sociais (organizaciones sociales, un tipo específico de asociación privada) presentado por el gobernador Sérgio Cabral y su secretario de salud, Sérgio Côrtes.

Palabras clave: Gestión de la salud; Sistema único de salud; Privatización; Medios de comunicación de masas; Organización social.

\footnotetext{
Contribuição dos autores:

Concepção e desenho do estudo: Débora Castanheira; Silvia Gerschman.

Aquisição, análise ou interpretação dos dados: Débora Castanheira; Clara Faulhaber.

Redação do manuscrito: Débora Castanheira; Clara Faulhaber.

Revisão crítica do conteúdo intelectual: Débora Castanheira; Silvia Gerschman.
}

Declaração de conflito de interesses: Este trabalho não apresenta conflito de interesses.

Fontes de financiamento: O presente trabalho foi realizado com apoio da Coordenação de Aperfeiçoamento de Pessoal de Nível Superior - Brasil (Capes) - Código de Financiamento 001.

Considerações éticas: não há.

Agradecimento/Contribuições adicionais: não há.

Histórico do artigo: Submetido: 07.dez.2017 | Aceito: 09.ago.2018 | Publicado: 25.set.2018.

Apresentação anterior: não houve.

Licença CC BY-NC atribuição não comercial. Com essa licença é permitido acessar, baixar (download), copiar, imprimir, compartilhar, reutilizar e distribuir os artigos, desde que para uso não comercial e com a citação da fonte, conferindo os devidos créditos de autoria e menção à Reciis. Nesses casos, nenhuma permissão é necessária por parte dos autores ou dos editores. 


\section{Introdução}

Desde a sua construção, o atual sistema de saúde brasileiro é palco da disputa entre modelos assistenciais distintos. Existem tendências conflitantes de reprodução dos modelos médico-assistenciais. Por um lado, o modelo privatista, com ênfase na assistência médico-hospitalar e nos serviços de diagnóstico e terapêutico; e, por outro, o sanitarista, fruto do movimento de Reforma Sanitária Brasileira (RSB)'1, que aposta na prevenção e na modificação dos determinantes sociais de saúde.

A conjuntura política de transição para a democracia favoreceu as propostas de mudança defendidas por um intenso movimento, iniciado por uma comunidade de especialistas e ampliado com o envolvimento de outros grupos de interesse, que acabou por elaborar a proposta de RSB. A Constituição Federal de 1988 aparentemente consagra o modelo sanitarista e o Sistema Único de Saúde (SUS) como a tradução setorial e institucional da proposta de um sistema nacional de acesso universal e integral.

Entretanto, já existia um robusto setor privado de saúde que não podia ser ignorado. Por um lado, o seguro privado de saúde era utilizado por parcela significativa da população. Por outro, e mais relevante, o parque hospitalar brasileiro era predominantemente privado, com destaque para o setor de entidades privadas sem fins lucrativos. O modelo que emerge nos anos 1990 é de um sistema de saúde nacional e universal, que conta com um segmento suplementar de planos privados de saúde, mas cujos serviços de assistência - principalmente de média e alta complexidade - são prestados quase que exclusivamente por hospitais privados.

O compromisso do SUS passa a ser com o aumento da rede hospitalar própria. Mas as relações pautadas historicamente pelas instituições públicas e privadas na saúde constrangem ou limitam uma nova institucionalidade do setor público e dos serviços de saúde nas instâncias federativas, estaduais e municipais que compõem o SUS². Além disso, a implementação do SUS na década de 1990 ocorreu em um cenário de viés ideológico neoliberal que propugnava a ampliação das relações comerciais na prestação de serviços, inclusive relativos à saúde, e uma redução no papel do Estado como provedor direto desses serviços.

Uma das questões centrais do debate na área da saúde diz respeito à implantação de novas formas de gestão e provisão de seus serviços. As alternativas que surgiram apontaram para a transformação do papel do Estado, com a substituição paulatina das funções de financiamento e provisão de serviços para a função de regulação da produção. No final dos anos 1990, entraram em vigor as primeiras leis que tratam da prestação privada de serviços públicos de saúde. A Lei 9.637, de 15 de maio de 1998, conhecida como Lei das Organizações Sociais (OSs) e a Lei 9.790, de 23 de março de 1999, denominada Lei das Organizações da Sociedade Civil de Interesse Público (OSCIP) regulavam os vínculos do setor público com entidades sem fins lucrativos. Posteriormente, a Lei 11.079, de 30 de dezembro de 2004, mais conhecida como a Lei das Parcerias Público-Privadas (PPPs), previu a possibilidade de participação de entidades com fins lucrativos. Como tentativa de contraposição a esse projeto neoliberal, vemos a proposta de Fundações Estatais de Direito Privado (FEDP) desenvolvida durante a presidência de Luiz Inácio Lula da Silva.

A expansão do setor privado no interior do SUS muda de figura. Sua principal forma deixa de ser a contratação de serviços hospitalares da rede privada e passa a ser o repasse da gestão do SUS para entidades privadas, com a implantação de novos modelos de gestão ${ }^{3}$. Com base nesse esboço jurídico, vários estados e municípios brasileiros passaram a transferir o gerenciamento dos serviços de saúde a entidades privadas, sob a forma de contratos de gestão, com a transferência de bens móveis, recursos humanos e financeiros. Em 2016, todos os 26 estados e o Distrito Federal possuíam legislação específica sobre a instalação de OSs ou das OSCIP para a gestão da saúde estadual.

Não obstante essa tendência geral, a trajetória político-institucional do SUS tem assumido ritmos e formas diferentes em cada unidade da Federação, principalmente em decorrência da correlação de forças de cada conjuntura. No estado do Rio de Janeiro, a mudança do modelo de gestão da saúde ganha impulso 
com os governos de Sérgio Cabral (2007-2011 e 2011-2015), e a regulamentação foi feita pela Lei 6.043, de 19 de setembro de $2011^{4}$. A aprovação nesta data pode ser considerada tardia quando a comparamos com o cenário nacional. De fato, sete estados aprovaram a sua legislação ainda nos anos $1990^{\mathrm{i}}$ e onze no início dos anos $2000^{\mathrm{ii}}$.

Esse fato levanta algumas perguntas interessantes: por que o governo de Sérgio Cabral logrou realizar a transição de paradigma de gestão enquanto outros com situação semelhante, como o governo de Marcelo Alencar (1995-1999), não conseguiram? Diante da inexistência de estabilidades institucionais e políticas significativas, quais fatores influenciam o sucesso e o fracasso na formulação da política de saúde no estado do Rio de Janeiro? Quais foram os recursos mobilizados pelo Poder Executivo para garantir a mudança?

Considerando esse contexto, este artigo tem como objetivo compreender o papel dos meios de comunicação de massa na formulação da agenda governamental de saúde no Rio de Janeiro no período da mudança do modelo de gestão de serviços de saúde. A hipótese é que a mídia foi o ator principal nesse processo, ao fazer um enquadramento da questão da saúde no estado análoga à perspectiva do governador e do secretário estadual de saúde. Os argumentos de ambos facilitaram um acesso aos marcos interpretativos mais gerais construídos socialmente, permitindo as pessoas conferirem sentido aos eventos e às situações sociais.

É importante observar que este artigo trata do papel da mídia apenas no que concerne à alteração do modelo de gestão da saúde no estado. Por esse motivo, não trataremos do, sem dúvida relevante, tema da relação entre os veículos midiáticos e outros aspectos da política fluminense (como, por exemplo, o processo eleitoral) e tampouco do impacto da concentração dos meios de comunicação.

\section{Contexto das gestões da saúde no Rio de Janeiro}

Com a consolidação do SUS, o estado do Rio de Janeiro segue a tendência nacional de ampliação não só das atribuições públicas na prestação de serviços de saúde, expressas no incremento dos orçamentos governamentais (os investimentos próprios em saúde passam de pouco menos de um bilhão e meio em 2003 para mais de três bilhões em 2011), mas também da capacidade instalada de estabelecimentos e, ainda, da cobertura ${ }^{3}$.

\footnotetext{
i São Paulo (Lei Complementar 846/1998), Maranhão (Lei 7.066/1998), Espírito Santo (Lei Complementar 158/1999). Merecem destaque, ainda, o pioneirismo de alguns estados ao promulgarem leis estaduais sobre o tema que antecederam a Lei federal de OSs, tais como o Pará (Lei 5.980/1996), a Bahia (Lei 7.027/1997), o Ceará (Lei 12.781/1997) e Roraima (Lei 174/1997).

ii Pernambuco (Lei 11.743/2000), Mato Grosso do Sul (Lei 2.152/2000), Amapá (Lei 599/01), Acre (Lei 1.428/2002), Minas Gerais (Lei 14.870/2003), Sergipe (Lei 5.217/2003), Mato Grosso (Lei Complementar 150/2004), Rio Grande do Norte (Lei Complementar 271/2004), Santa Catarina (Lei 12.929/2004), Goiás (Lei 15.503/2005) e Piauí (Lei 5.519/2005). Na segunda metade dos anos 2000, foram aprovadas as leis de Paraíba (Lei Complementar 74/2007), Rio Grande do Sul (Lei 12.901/2008) e Distrito Federal (Lei 4.081/2008). Rondônia (Lei 2.675/2011), Paraná (Lei Complementar 140/2011) e Tocantins (Lei 2.427/2011) aprovaram no mesmo ano que o Rio de Janeiro e Amazonas (Lei 3.900/2013) e Alagoas (Lei 7.777/2016) aprovaram depois.
} 
Tabela 1 - Estabelecimentos de saúde por esfera administrativa e cobertura da Estratégia Saúde da Família - 2002, 2005 e 2009

\begin{tabular}{|c|c|c|c|c|c|c|}
\hline \multirow[t]{2}{*}{ Ano } & \multirow[t]{2}{*}{ Unidade Geográfica } & \multicolumn{4}{|c|}{ Estabelecimentos de saúde* } & \multirow{2}{*}{$\begin{array}{c}\text { Cobertura ESF } \\
\text { (em \% da população) }\end{array}$} \\
\hline & & Total & Pública & Privada & Privada/SUS & \\
\hline \multirow{3}{*}{2002} & Brasil & 53825 & 37674 & 16151 & 4976 & 35,69 \\
\hline & Sudeste & 19023 & 11797 & 7226 & 1685 & 26,48 \\
\hline & Rio de Janeiro & 3496 & 1706 & 898 & 55 & 19,48 \\
\hline \multirow{3}{*}{2005} & Brasil & 62483 & 43987 & 18496 & 4966 & 44,35 \\
\hline & Sudeste & 21907 & 13865 & 8042 & 1682 & 32,11 \\
\hline & Rio de Janeiro & 3843 & 1907 & 1936 & 334 & 26,55 \\
\hline \multirow{3}{*}{2009} & Brasil & 74776 & 50253 & 24523 & 5232 & 50,69 \\
\hline & Sudeste & 26806 & 15821 & 10985 & 1851 & 38,07 \\
\hline & Rio de Janeiro & 4799 & 2279 & 2520 & 1196 & 31,05 \\
\hline
\end{tabular}

Fonte: Adaptado de IBGE $^{5}$

*Nota: Exceto estabelecimentos de apoio à diagnose.

No estado do Rio de Janeiro, podemos acompanhar também um crescimento, ainda que não muito expressivo, da capacidade instalada do setor público. No entanto, ao contrário da tendência nacional, existe um incremento significativo no número de estabelecimentos privados, apoiado, em grande parte, na venda de serviços ao estado. Como podemos observar na Tabela 1, quase metade da rede privada (47,5\%) estava integrada ao Sistema Único de Saúde em 2009, mais do que a média nacional e muito superior ao valor para a Região Sudeste (16,8\%).

Portanto, ao contrário da trajetória nacional descendente de contratação de estabelecimentos privados para a prestação de serviços públicos, o estado do Rio de Janeiro aumentou a participação nesse setor durante os anos 2000. Esta peculiaridade da gestão da saúde no estado pode ser atribuída à implantação tardia da Estratégia Saúde da Família (ESF) no território fluminense.

Com efeito, a capacidade instalada do setor público parece seguir um padrão de expansão similar à cobertura de serviços de atenção básica. Os municípios do estado do Rio de Janeiro, no entanto, se caracterizaram por um lento aumento da oferta desse tipo de serviços. O caso do município do Rio de Janeiro é exemplar. Em 2008, a cobertura de equipes de saúde da família correspondia a 3,5\% de sua população, a mais baixa entre as capitais ${ }^{6}$. A baixa cobertura dos municípios faz com que a cobertura fluminense seja muito inferior à brasileira: em 2008, apenas 28,65\% da população do estado era coberta pela ESF, enquanto a média nacional era 47,32\%. A partir de 2009, a cobertura cresce progressivamente, com a implantação do programa no território.

A lentidão na estruturação dos serviços de atenção básica no território do Rio de Janeiro afeta a gestão dos serviços de saúde, pelo menos, de duas formas: aumento da demanda por emergências e aparecimento tardio da questão da gestão do trabalho em saúde. Por um lado, a falta de acesso à atenção primária à saúde (APS) e, principalmente, a uma fonte regular de cuidado acaba por aumentar a demanda por serviços emergenciais ${ }^{7-10}$. A carência de longitudinalidade no atendimento desloca a atenção da rede assistencial para serviços, em parte, de responsabilidade da esfera estadual que tem que lidar com um aumento imprevisto da demanda.

No estado do Rio de Janeiro, a situação se agrava em razão das decisões de gestão adotadas pelo governo da capital - responsável, por razões históricas por parte considerável dos serviços de urgência e emergência ${ }^{11}$ - que culminam, em 2005, com a federalização de seis unidades hospitalares sob a alegação 
de "estado de calamidade pública no setor hospitalar do SUS no município do Rio de Janeiro" ${ }^{12}$. Assim, além da pouca cobertura dos serviços de APS, o Rio de Janeiro também tinha parte de suas unidades de emergência com funcionamento precário.

A questão da gestão dos serviços de saúde no território do Rio de Janeiro poderia, portanto, ser interpretada e apresentada ao público como um problema de baixa cobertura de serviços de APS que acabam por sobrecarregar as emergências com demanda indevida. Na verdade, essa é a interpretação tradicionalmente realizada pela comunidade acadêmica especializada ${ }^{13}$. Neste caso, as alternativas de solução passariam pela integração vertical da gestão, na qual o governo do estado assumiria o papel de coordenar e impulsionar, com recursos técnicos e financeiros, a implantação dos programas de atenção básica, buscando convergência dentro de uma perspectiva de regionalização da saúde. Esse tipo de enquadramento da questão e as soluções para o problema dele decorrente são mais próximas da valorização do SUS, do que as que encontramos em períodos anteriores da gestão estadual, incluindo o período imediatamente anterior, ou seja, o do governo de Rosinha Matheus (2003-2006).

O governo do estado do Rio de Janeiro, no mandato de Sérgio Cabral, responde a esses desafios reinterpretando a questão da gestão da saúde no território como um problema de falta de capacidade instalada para atender demandas emergenciais. A solução é outra, passa pelo aumento de sua capacidade assistencial de emergência através das unidades de pronto atendimento (UPA). O programa começa a ser implantado em 2007 como uma proposta alternativa de solução para os dilemas enfrentados no estado que não passasse pela negociação intergovernamental necessária para organização da rede assistencial. Neste sentido, ao enquadrar a questão da gestão da saúde fluminense não como um problema de coordenação federativa para implementação de redes, mas de deficiência na prestação de serviços emergenciais, o governo do estado do Rio de Janeiro reinventou a posição estadual no SUS.

As UPAs criadas em 2007 para desafogar as emergências no estado foram desenvolvidas para funcionar sob o modelo de administração direta, com a corporação militar dos bombeiros assumindo funções de gerência e assistência nas unidades entre 2007 e 2010. As UPA rapidamente se tornaram o principal projeto de saúde do governo do estado e um de seus carros-chefes eleitorais. A utilização de profissionais militares visava cobrir alguns dos principais problemas de gestão do trabalho em saúde apontados em nossa pesquisa, quais sejam: a contratação e fixação profissionais de saúde, principalmente médicos, em áreas periféricas ou de maior violência urbana.

No entanto, em 2011, um grupo representativo de membros do Corpo de Bombeiros iniciou protestos que, mais tarde, evoluiriam para amotinamentos e prisões, exigindo melhorias para a categoria. Entre as reivindicações, podemos destacar: melhores condições de trabalho, aumento salarial e a desvinculação entre a Secretaria de Defesa Civil (Sedec) e a Secretaria de Estado de Saúde (SES), vinculadas desde janeiro de 2007 para permitir a gestão das UPA.

O descontentamento dos bombeiros militares, sua paralisação e recusa a continuar com a gerência e prestação de serviço nas UPA gerou uma crise na prestação de serviços, uma vez que o atendimento nas unidades criadas dependia bastante deles, não havia pessoal concursado para ocupá-las. Essa situação, causada principalmente pela ausência de uma política coerente de gestão do trabalho em saúde, foi que deu início às alterações do modelo de gestão da saúde no estado. A maneira como o assunto foi construído como um problema a ser tratado na agenda pública é essencial. Em vez de ser apresentado como um problema de gestão do trabalho (o que levaria a uma valorização do serviço público e da prestação de serviços direta), ele foi construído como uma crise da capacidade do setor público para administrar serviços e contratar pessoal.

A mudança no discurso pode parecer pequena e sem maiores consequências, mas, ao definir a questão como um problema de rigidez burocrática e ineficiência na administração de recursos, o conjunto de soluções possíveis abandona a valorização do serviço público e passa a orbitar em torno de modelos de gestão de serviços de saúde. Buscando inspiração no vocabulário neoliberal, o governo do estado do Rio de Janeiro 
se volta para os instrumentos gerenciais criados na década de 1990 com base nas recomendações do Consenso de Washington, cujas diretrizes enfatizavam a flexibilização dos mercados nacional e internacional, das relações de trabalho, da produção e dos investimentos financeiros, e o afastamento do estado das suas responsabilidades sociais e da regulação social entre capital e trabalho. Este tipo de apresentação da questão da saúde redefine os limites do público e do privado como solução para os problemas de gestão de serviços públicos.

Assim, podemos dizer que o governador Sérgio Cabral e o seu secretário de Saúde, Sérgio Côrtes, empreenderam a mudança na política de gestão da saúde por meio de sucessivos enquadramentos da questão da saúde no território fluminense, primeiramente rearticulando-a como um problema de atendimento emergencial e, posteriormente, como um problema da ineficiência do setor público na gestão de recursos humanos. Nesse processo, o papel dos meios de comunicação de massa foi fundamental porque quais assuntos são abordados e o modo como são caracterizados pela mídia pode influenciar o entendimento do público sobre a temática retratada ${ }^{14}$.

\section{O papel da mídia na construção de problemas de políticas públicas}

A multiplicidade das relações sociais cria, a todo momento, diversas situações que podem ser percebidas como problemas sociais. Contudo, nem todas as situações são percebidas como problemas e nem todos os problemas passam a concentrar a atenção do governo e de pessoas ligadas a ele, ou seja, nem todos os problemas fazem parte da agenda governamental. Para entender esse processo, Kingdon ${ }^{15}$ estabelece uma divisão entre problemas e tópicos (conditions).

Um tópico é uma situação social percebida, mas que não desperta necessariamente uma ação em contrapartida. Esse tipo de questão configura-se como problema apenas quando os atores participantes da formulação da política o assumem como passível de intervenção estatal. Por este motivo, a inclusão de qualquer tópico na agenda fica marcada pela forma como esses atores os percebem e os interpretam e, mais importante, pela forma como eles são definidos como problemas.

Ou seja, apesar de os formuladores da política não terem controle completo sobre o que entra na agenda - uma vez que estão limitados a um conjunto de tópicos sociais - eles definem, em grande parte, quais dos tópicos merecem atenção naquele momento e, além disso, a forma como a questão será elaborada e levada ao público para discussão. A entrada de um tópico na agenda passa pela construção de uma base argumentativa que justifique a intervenção estatal. Dessa forma, a formulação de políticas públicas está situada entre o 'poder' e a 'racionalidade', entre a satisfação de interesses e a argumentação substantiva ${ }^{16}$. Nesse sentido, a política pública implica todo um conjunto de atividades pré e pós-decisões que buscam aportar em "evidências, argumentos e persuasão" ${ }^{17}$ com o fim de obter consenso.

Esses argumentos são geralmente de três ordens: indicadores; eventos, crises e símbolos; além de feedback das ações governamentais ${ }^{15}$. É importante notar que a presença desses elementos não transforma tópicos em problemas, que, na verdade, são construções sociais que envolvem a interpretação dos atores responsáveis pela formulação das políticas públicas. Do ponto de vista da estratégia política, a definição do problema é fundamental. A forma como um problema é definido, articulado, concentrando a atenção dos atores envolvidos na formulação da política, pode determinar o êxito de uma questão no processo altamente competitivo de criação da agenda.

Nesse processo, o papel dos meios de comunicação de massa é fundamental porque o modo como um assunto é caracterizado pela mídia pode influenciar o entendimento do público sobre a temática retratada ${ }^{14}$. A ideia aqui implicada é tributária de décadas de pesquisa existente em sociologia ${ }^{18}$, psicologia ${ }^{19}$, linguística $\operatorname{cognitiva~}^{20} \mathrm{e}$ comunicação $0^{21,22}$. A novidade é seu uso para a análise sistemática do papel da mídia na entrada de problemas na agenda governamental ${ }^{23}$. 
A expansão da base de apoio na opinião pública para suas decisões torna-se tanto mais relevante quanto maior a controvérsia sobre o tema. Isso significa que, quando a definição do problema é polêmica dentro de uma comunidade de especialistas ou de movimentos sociais, o apoio da mídia é importante para angariar apoio para as proposições. A relevância política da imprensa, portanto, aumenta sensivelmente durante controvérsias públicas ${ }^{24}$. Temas controversos tendem a desestabilizar explicações correntes de problemas antigos, abrindo espaço para que sejam apresentados e difundidos novos pacotes interpretativos para o grande público ${ }^{25}$.

A definição de um problema implica enquadrá-lo em uma categoria, realçando determinados aspectos e esmorecendo outros ${ }^{26}$. O conceito de enquadramento assinala que existem diversas formas de entender uma questão social. Isso significa que perceber e interpretar a realidade social só é possível com a adoção de uma perspectiva, uma moldura, em razão do próprio trabalho de dar sentido a situações complexas requerer seleção e organização de informações ${ }^{27}$.

O enquadramento do problema determina como a questão será percebida e quais soluções parecerão relevantes. Isso acontece porque o enquadramento é baseado em "modelos específicos de agência, causalidade e responsabilidade" ${ }^{28}$, ou seja, ele nos diz sobre o que o problema trata, por que aconteceu, quem são os possíveis responsáveis e o que pode ser feito para resolvê-lo. Além disso, o tipo de enquadramento tem impacto sobre que atores serão mais aptos a atuar no processo de formulação e implementação da política; isso porque a maneira como um problema é representado afeta a percepção dos atores sobre perdas e ganhos $^{29}$.

A definição do problema é, portanto, uma atividade política na qual grupos competem por interpretações alternativas de uma questão social. Existe uma disputa simbólica pela representação social de um problema, na qual está em jogo não apenas a caracterização da questão, mas também o que deve ser feito ${ }^{28}$.

Com isso, a influência da mídia sobre a entrada de questões na agenda foi muito bem colocada por Cohen $^{30}$, segundo o qual a imprensa "pode não ser bem-sucedida na maior parte do tempo em dizer para as pessoas o que pensar, mas é incrivelmente exitosa em dizer aos leitores sobre o que devem pensar”. Assim, a mídia chama a atenção para alguns assuntos. Ao escolher e apresentar notícias, a imprensa tem um papel importante na construção da realidade política. O grande volume de informações com o qual o público se depara todos os dias torna impossível que ele analise detidamente cada uma; por isso, os receptores das notícias passam a atribuir importância aos assuntos de acordo com o tempo e a posição que eles ocupam na imprensa ${ }^{31}$.

O conteúdo do que é tratado na mídia também tem um impacto importante ${ }^{32}$. Como a principal fonte de informação sobre os temas da esfera pública continua sendo aquela apresentada pelos meios de comunicação de massa, a maneira como eles escolhem apresentar seus temas pode acabar por afetar a forma como as pessoas definem o problema e pensam em soluções mais adequadas. Existe um grande número de trabalhos que demonstram a importância de diferentes veículos de comunicação na definição do debate público ${ }^{25,33-36}$. A maior parte deles trabalha com a premissa de que a mídia exerce sua influência no debate público filtrando e realçando aspectos de determinado tema, inclusive dando voz a alguns atores sociais e silenciando outros.

Assim, podemos dizer que os meios de comunicação podem potencialmente desempenhar um papel ativo e continuado, influenciando e refletindo a construção da agenda ${ }^{37}$. A mídia pode influenciar a formação de políticas ao gerar a atenção do público e, através dela, a pressão política para que certos atores passem a atuar sobre uma questão particular ${ }^{38}$. A cobertura da mídia, porém, não só aumenta as percepções e a atenção públicas sobre várias questões, mas as constrói, definindo-as como econômicas ou políticas, sociais ou pessoais, radicais ou conservadoras. O que é relatado, como é relatado, quem relata e o caráter do meio de comunicação têm implicações para a mensagem da mídia ao público ${ }^{39}$. Por outro lado, é importante atentar para a maneira como a mídia trata um tópico. Ela não é capaz de determinar a opinião pública, pois a recepção será mediada pelas estruturas sociais nas quais o sujeito está inserido, mas tem um importante 
papel em condicioná-la, uma vez que limita os tópicos sobre os quais o público terá informação, bem como o tipo e a quantidade dessa informação ${ }^{40}$.

Embora questionada sob muitos aspectos ${ }^{41}$ a análise do enquadramento apresenta uma oportunidade de sistematizar grandes volumes de dados, produzidos em diferentes períodos e/ou por diversas fontes. Ela tem a vantagem de permitir enxergar as rupturas e continuidades nas representações dos assuntos pela mídia, com base em um denominador comum.

A hipótese do enquadramento aponta para uma das maneiras pelas quais a imprensa exerce o papel de ator político. Sabemos que a grande imprensa contemporânea cultiva, para fins de legitimação de sua função, o valor da imparcialidade - um desenvolvimento histórico que Bernard Manin atribui ao advento da democracia de público ${ }^{42}$. Quando tratamos de uma imprensa que, em determinado momento, opera selecionando, filtrando e realçando aspectos de uma questão, trabalhamos implicitamente com o pressuposto de que essa imparcialidade é falsa e de que tal valor é violado na própria maneira como a notícia é apresentada ao público.

Esse processo é natural, uma vez que o relato de qualquer situação depende do background político e cultural de quem publica a notícia. Nesse sentido, valores jornalísticos como neutralidade, imparcialidade e objetividade devem ser entendidos como parâmetros que ajudam o jornalista a definir as "redes de facticidade" ${ }^{23}$, isto é, o que conta ou o que não conta como fato para a mídia. São princípios que guiam a atividade jornalística, mas que não são necessariamente atingíveis pela própria estrutura do processo de produção de conteúdo. Eles podem ser entendidos também como padrões sistemáticos de conhecimento, interpretação e apresentação, de seleção, ênfase e exclusão pelos quais os veículos de comunicação organizam o discurso.

Contudo, os enquadramentos podem ser utilizados com o objetivo de manipular ativamente o conteúdo das reportagens/notícias veiculadas. Nesses casos, os veículos de comunicação atuariam como atores políticos quando utilizarem o enquadramento para passar deliberadamente uma imagem para o público. É importante lembrar que, como os meios de comunicação se comportam de maneira diferente dependendo do tema a ser veiculado ao público (vale dizer, dependo dos interesses políticos e econômicos atrelados a cada questão), nada impede que os mesmos meios de comunicação exerçam seu papel de ator político de outras formas, dependendo do que é tratado. Em algumas situações, a mídia pode assumir, por exemplo, o papel de administradora do espaço público onde ocorrem as disputas, dando espaço para que diferentes grupos se manifestem ${ }^{24}$.

Para determinar o papel da mídia na transição do modelo de gestão da saúde no território fluminense, o presente artigo identifica se a questão da saúde é colocada na agenda nos períodos considerados e a existência de um viés na cobertura midiática sobre a mudança de modelo de gestão das unidades assistenciais de saúde no estado do Rio de Janeiro. Posteriormente, demonstra-se como tal viés é articulado, isto é, como ele se expressa por meio dos diferentes textos veiculados nos jornais de maior circulação publicados no estado e qual é o seu conteúdo argumentativo. Cada uma destas partes tem uma metodologia específica, que será desenvolvida no tópico seguinte.

\section{Metodologia e dados}

A fonte dos dados utilizados neste artigo foi o conjunto de clippings sobre temas relacionados à saúde pública realizado pelo Programa RADIS de Comunicação e Saúde, um programa nacional e permanente de jornalismo crítico e independente em saúde pública, iniciado em 1982, na Escola Nacional de Saúde Pública Sérgio Arouca (ENSP/Fiocruz). O programa reúne um conjunto de notícias publicadas em periódicos impressos de circulação nacional e nos estados brasileiros (periódicos com circulação restrita a cidades ou organizações territoriais menores não fazem parte do acervo). 
A partir do arquivo RADIS, foram selecionadas apenas reportagens e notícias - ou seja, o levantamento não inclui cartas, artigos, colunas, editoriais, entrevistas e resenhas - sobre gestão da saúde publicadas entre 2003 e 2011 nos três jornais de maior circulação no estado do Rio de Janeiro: O Globo, Extra (também do Grupo Globo) e O Diaiii. O jornal O Globo tem circulação nacional e possui como público-alvo os estratos socioeconômicos A e B, enquanto Extra e O Dia têm circulação estritamente local e são direcionados para os estratos C, D e E.

O tema gestão da saúde incluiu temas relacionados ao financiamento, provisão de serviços, relações federativas e intersetoriais, além de monitoramento e avaliação da prestação de serviços públicos e privados. Portanto, não foram tratadas na pesquisa as notícias relacionadas ao aumento de doenças crônicas na população, epidemias, pandemias, avanços científicos relacionados à prevenção ou tratamento etc.

Utilizamos a mídia jornalística impressa como proxy do comportamento dos meios de comunicação em geral. Não desconsideramos que o meio televisivo e a imprensa apresentam diferentes pesos no que toca ao agendamento. Comparando a outras mídias, a TV tem muito maior impacto e abrangência na construção de imaginários sociais da população brasileira, principalmente em razão de sua disseminação (de acordo com dados do Censo 2010, 95,1\% dos lares brasileiros têm aparelho de televisão) e da queda dos índices de leitura e tiragem de mídia impressa ${ }^{28}$. Contudo, em razão do monopólio familiar e da propriedade cruzada dos meios de comunicação de massa no Brasil, os dois veículos jornalísticos de maior circulação (O Globo e Extra) fazem parte do grupo proprietário da líder em televisão aberta, Rede Globo. Por este motivo é possível utilizar as publicações nos jornais para averiguar como ocorre a filtragem e seleção dos assuntos na mídia fluminense.

Posteriormente, as notícias foram agrupadas de acordo com o seu conteúdo em oito categorias: 1) Crise: incluiu reportagens e notícias que caracterizam a situação de saúde no estado do Rio de Janeiro como uma situação crítica ou de emergência; 2) Unidades de saúde: ao contrário da categoria anterior, neste caso, as notícias tratam de problemas em locais específicos, como hospitais e postos de saúde; 3) Planos de saúde; 4) Programas da SES: trata de programas específicos levados à frente pela Secretaria que, na gestão de Rosinha Matheus, são variados (cheque-cidadão, farmácia popular, restaurante popular etc.) e no governo Sérgio Cabral significa a implantação das UPA; 5) Financiamento da saúde: discussões sobre a EC 29/oo ${ }^{\text {iv }}$, sua regulação e CPMF; 6) Coordenação: intersetorial (entre a Secretaria de Saúde e outras secretarias, como a de assistência social ou educação) e interfederativa (entre as esferas de governo, federal, estadual e municipal); 7) Modelo de gestão: reúne o debate feito em torno das alternativas de gestão privada de serviços públicos no Rio de Janeiro; 8) Outros.

É importante notar que este trabalho trata apenas da gestão estadual de saúde e, por este motivo, notícias sobre as municipalidades só são relacionadas quando seu conteúdo faz referência explícita à sua associação com a rede estadual. Isso é importante especialmente no que diz respeito ao ano de 2005, quando, diante da alegação de calamidade pública no setor hospitalar municipal, o governo federal requisitou bens, serviços e servidores relativos a seis hospitais: quatro unidades federais que haviam sido municipalizadas em $1999 \mathrm{e}$ dois grandes hospitais municipais de emergência. O volume de notícias na categoria 'crise' aquele ano foi, é claro, enorme. Contudo, como elas se referiam exclusivamente à rede da capital, não fazem parte dessa compilação. O mesmo acontece com diversos municípios da Baixada Fluminense entre 2007 e 2009.

iii O Jornal do Brasil, a quarta publicação com maior distribuição no Rio de Janeiro, teve sua versão impressa descontinuada em 2010, o que impede acompanhamento da questão da gestão privada de serviços públicos por todo período exigido por nossa pesquisa. Em razão dessa limitação de nossa fonte de dados, optamos por não utilizar o material recolhido nesse veículo de comunicação.

iv A Emenda Constitucional 29/00 altera os arts. 34, 35, 156, 160, 167 e 198 da Constituição Federal e acrescenta artigo ao Ato das Disposições Constitucionais Transitórias, para assegurar os recursos mínimos para o financiamento das ações e serviços públicos de saúde. 
As reportagens e notícias sobre 'crise' foram organizadas em subcategorias, baseadas nos motivos dados pelos veículos de imprensa para a existência da situação crítica: má gestão orçamentária, falta de recursos físicos (leitos para internação, unidades de emergência etc.), falta de recursos humanos, corrupção, falta de cobertura da atenção básica, relações interfederativas (repasse de verbas) e outros.

\section{Resultados: a gestão estadual de saúde na mídia fluminense}

Como é possível observar na Tabela 2, existe uma diferença marcante no número absoluto de reportagens e notícias (110 - 85\%) publicadas sobre gestão da saúde nos governos de Rosinha Matheus (2003-2006) e no primeiro governo de Sérgio Cabral (2007-2010). O número de notícias permanece alto até 2007, ano a partir do qual sofre uma queda brusca. Em números absolutos, o ano com maior número de reportagens e notícias é 2007 (21,6\%) e o menor 2011 (3,9\%).

A questão dos programas desenvolvidos na área da saúde aparece apenas no início dos respectivos mandatos, com notável número de reportagens e notícias criticando o modelo de gastos adotado pela gestão de Rosinha (74,1\%), que utilizou recursos da saúde para financiar programas focalizados de transferência de renda e de alimentação. As reportagens e notícias sobre os programas da SES no período de Cabral se concentram nas UPA, que são consideradas um incremento positivo à rede pública em todas as reportagens e notícias analisadas (25,9\%).

A mudança do modelo de gestão de serviços públicos surge como tema da agenda da mídia apenas no governo de Cabral. Sua aparição é intermitente e segue o padrão da agenda política do Executivo. Ou seja, reportagens e notícias (92,3\%) sobre privatização de serviços públicos surgem em função dos projetos de lei enviados para a Assembleia Legislativa do Estado do Rio de Janeiro (Alerj). Assim, podemos observar que, quando o tema surge em 2007, ele trata de Fundação Pública de Direito Privado (FPDP), em 2009 de uma proposta de Parceria Público Privada e em 2011 de Organizações Sociais. No entanto, enquanto em 2007 e 2009 cerca de metade das reportagens e notícias $(46,2 \%)$ tinham caráter crítico, apresentando instituições e figuras públicas contrárias ao projeto, em 2011 o tom das notícias é absolutamente positivo e de apoio ao governo. As opiniões e análises contrárias passam a ser apresentadas como notas em reportagens e notícias positivas e não levam a exame posterior (19,2\%). 
Tabela 2 - Notícias sobre gestão da saúde publicadas no RJ, por categoria e ano ( $n^{\circ}$ e \%), 2003-2011

\begin{tabular}{|c|c|c|c|c|c|c|c|c|c|c|c|c|c|c|c|c|c|c|}
\hline & \multicolumn{2}{|c|}{2003} & \multicolumn{2}{|c|}{2004} & \multicolumn{2}{|c|}{2005} & \multicolumn{2}{|c|}{2006} & \multicolumn{2}{|c|}{2007} & \multicolumn{2}{|c|}{2008} & \multicolumn{2}{|c|}{2009} & \multicolumn{2}{|c|}{2010} & \multicolumn{2}{|c|}{2011} \\
\hline & $n$ & $\%$ & $n$ & $\%$ & $n$ & $\%$ & $n$ & $\%$ & $\mathrm{n}$ & $\%$ & $\mathrm{~N}$ & $\%$ & $\mathrm{~N}$ & $\%$ & $n$ & $\%$ & $n$ & $\%$ \\
\hline Crise & 240 & 42,1 & 210 & 45,7 & 200 & 74,1 & 310 & 53,4 & 290 & 40,6 & 80 & 44,4 & 120 & 50 & 100 & 62,5 & 30 & 23,1 \\
\hline Coordenação & 60 & 10,5 & 140 & 30,4 & 40 & 14,8 & 30 & 5,3 & 110 & 15,4 & 5 & 2,8 & 30 & 12,4 & 10 & 6,3 & 0 & 0 \\
\hline $\begin{array}{l}\text { Unidade } \\
\text { de saúde }\end{array}$ & 50 & 8,8 & 0 & 0 & 0 & 0 & 170 & 29,3 & 130 & 18,2 & 50 & 27,8 & 5 & 2,1 & 10 & 6,3 & 20 & 15,3 \\
\hline $\begin{array}{l}\text { Programas } \\
\text { da SES }\end{array}$ & 130 & 22,8 & 60 & 13 & 10 & 3,7 & 0 & 0 & 40 & 5,6 & 10 & 5,6 & 0 & 0 & 20 & 12,5 & 10 & 7,7 \\
\hline Financiamento & 70 & 12,3 & 10 & 2,2 & 10 & 3,7 & 10 & 1,7 & 0 & 0 & 20 & 11,1 & 5 & 2,1 & 0 & 0 & 10 & 7,7 \\
\hline $\begin{array}{l}\text { Modelo de } \\
\text { gestão }\end{array}$ & 0 & 0 & 0 & 0 & 0 & 0 & 10 & 1,7 & 80 & 11,2 & 0 & 0 & 40 & 16,7 & 0 & 0 & 50 & 38,5 \\
\hline Outros & 20 & 2,5 & 40 & 8,7 & 10 & 3,7 & 50 & 8,6 & 65 & 9,0 & 15 & 8,3 & 40 & 16,7 & 20 & 12,5 & 10 & 7,7 \\
\hline otal & 570 & 100 & 460 & 100 & 270 & 100 & 580 & 100 & 715 & 100 & 180 & 100 & 240 & 100 & 160 & 100 & 130 & 100 \\
\hline
\end{tabular}

Fonte: Os autores (2018).

As reportagens e notícias da categoria 'crise' são as mais presentes em todos os anos, com exceção de 2011, no qual vemos a categoria 'modelo de gestão' emergir como a mais presente. O ano de 2005 é o que tem maior percentual de notícias sobre 'crise' na gestão pública de saúde $(74,1 \%)$, mas em termos absolutos o ano com maior presença dessa categoria é 2006, com um total de 310 (53,4\%) reportagens e notícias. De modo geral, podemos dizer que o tema da crise está menos presente durante todo o período de governo de Cabral (são 590, o que significam 38,1\% reportagens e notícias enquanto, no governo de Rosinha, foram encontradas 960, ou seja, 61,9\%), e que isso se reflete no número total de reportagens e notícias de 2003 a 2010 (1.550) sobre a gestão da saúde no Rio de Janeiro.

As razões para o estado crítico ou emergencial da gestão da saúde variam no decorrer dos anos. Em 2003, a mídia apresenta como causa da crise a má gestão orçamentária, ou seja, o uso inadequado de recursos próprios e repassados pelo governo federal. Em 2004, 2006 e 2007, a falta de recursos físicos, ou seja, de leitos emergenciais e de serviços de média e alta complexidade é associada ao estado crítico. Em 2005, a mídia divide as razões entre falta de recursos físicos e de recursos humanos, principalmente de médicos. Em 2008, tem uma queda surpreendente das reportagens e notícias sobre crise em saúde (13\%), e as razões são novamente falta de recursos físicos e humanos. Em 2009, a questão dos recursos humanos surge com força (67\%), mas perde espaço interpretativo em 2010 (40\%), como se vê na Tabela 3. O ano de 2011 tem menos notícias sobre crise em saúde, tendo o foco revertido para a implantação das organizações sociais. 
Tabela 3 - Notícias da categoria crise, por subtema e ano (2003-2011)

\begin{tabular}{|c|c|c|c|c|c|c|c|c|c|c|c|c|c|c|c|c|c|c|}
\hline \multirow[b]{3}{*}{ Má gestão } & \multicolumn{2}{|c|}{2003} & \multicolumn{2}{|c|}{2004} & \multicolumn{2}{|c|}{2005} & \multicolumn{2}{|c|}{2006} & \multicolumn{2}{|c|}{2007} & \multicolumn{2}{|c|}{2008} & \multicolumn{2}{|c|}{2009} & \multicolumn{2}{|c|}{2010} & \multicolumn{2}{|c|}{2011} \\
\hline & $\mathrm{n}$ & $\%$ & $\mathrm{n}$ & $\%$ & $n$ & $\%$ & $n$ & $\%$ & $n$ & $\%$ & $n$ & $\%$ & $n$ & $\%$ & $n$ & $\%$ & $n$ & $\%$ \\
\hline & 100 & 42 & 40 & 19 & 0 & 0 & 70 & 23 & 50 & 17 & 10 & 13 & 0 & 0 & 0 & 0 & 0 & 0 \\
\hline $\begin{array}{l}\text { Recursos } \\
\text { humanos }\end{array}$ & 0 & 0 & 10 & 5 & 70 & 35 & 80 & 26 & 30 & 10 & 30 & 38 & 80 & 67 & 40 & 40 & 10 & 33 \\
\hline Recursos físicos & 70 & 29 & 130 & 62 & 80 & 40 & 130 & 42 & 130 & 45 & 20 & 25 & 10 & 8 & 40 & 40 & 0 & 0 \\
\hline Corrupção & 0 & 0 & 10 & 5 & 0 & 0 & 10 & 3 & 80 & 28 & 0 & 0 & 0 & 0 & 10 & 10 & 10 & 33 \\
\hline Cobertura AB & 30 & 13 & 10 & 5 & 10 & 5 & 0 & 0 & 0 & 0 & 20 & 25 & 30 & 25 & 10 & 10 & 10 & 33 \\
\hline $\begin{array}{l}\text { Relações } \\
\text { interfederativas }\end{array}$ & 30 & 13 & 0 & 0 & 40 & 20 & 10 & 3 & 0 & 0 & 0 & 0 & 0 & 0 & 0 & 0 & 0 & 0 \\
\hline Outros & 10 & 4 & 10 & 5 & 0 & 0 & 10 & 3 & 0 & 0 & 0 & 0 & 0 & 0 & 0 & 0 & 0 & 0 \\
\hline Total & 240 & 100 & 210 & 100 & 200 & 100 & 310 & 100 & 290 & 100 & 80 & 100 & 120 & 100 & 100 & 100 & 30 & 100 \\
\hline
\end{tabular}

Fonte: Os autores (2018).

Dois pontos extras merecem atenção. O primeiro é a pouca utilização de explicações ligadas à corrupção para explicar a suposta crise da gestão da saúde. Na verdade, a corrupção só aparece como fator importante em 2007 (28\%), justamente em razão da mudança de governo e de acusações sobre o estado das contas públicas deixado para a nova gestão. Isso é interessante em virtude da proporção que esse tipo de interpretação passa a ter a partir de 2016, com acusações de desvio de verbas e superfaturamento direcionadas ao então secretário de saúde Sérgio Côrtes no período estudado.

O segundo ponto relevante é o pouco volume de notícias, dentro da categoria 'crise', que consideram como razão principal a baixa cobertura da atenção básica nos municípios fluminenses (7,6\%). Apesar de estar presente em quase todos os anos, ela representa um número muito pequeno quando comparado com outras causas. Isso é de estranhar, uma vez que essa é a interpretação mais comum entre os especialistas da área. Parece apontar para uma dificuldade de acesso da comunidade especializada aos meios de comunicação de massa.

\section{Discussão: construção de uma imagem de crise e mudança do modelo de gestão}

A agenda da mídia é formada por um processo de filtragem dos assuntos que serão levados ao público ${ }^{43}$. Considerando que o espaço é limitado e que a atenção do público não pode se dividir por um número indefinido de questões, aquelas matérias enfatizadas pelos meios de comunicação acabam tornando-se igualmente importantes para o público ${ }^{44}$. Apesar de não ser possível através de nosso levantamento de dados comparar a atenção da mídia fluminense sobre o tema da gestão da saúde com outros assuntos, alguns estudos apontam para sua importância na agenda da mídia brasileira45-47.

Além de filtrar os assuntos, os meios de comunicação tentam conferir sentidos ao que é publicado através de um processo de interpretação dos acontecimentos, salientando determinados aspectos, tornando-os visíveis para o público. A informação que chega ao público, como não poderia deixar de ser, nunca é um relato completo e impessoal de acontecimentos, mas uma visão altamente seletiva e estereotipada de questões sociais. Assim, "os veículos de comunicação são mais do que simples canais de transmissão dos principais eventos do dia. Eles constroem e apresentam ao público um pseudo-ambiente, que significativamente condiciona como o público vê o mundo" ${ }^{4}$. Isso é verdade mesmo para tópicos que são experimentados diretamente pela audiência como, por exemplo, a saúde pública ${ }^{41}$. 
Partindo de categorias amplas, que atravessam temas específicos, os enquadramentos localizam os repertórios comuns acionados na enunciação de uma mensagem, que permitem à audiência compreendê-la e dar-lhe significado. Localizar o enquadramento dentro de uma notícia, portanto, significa identificar o conjunto de convenções criado pela mídia e acionado no momento da representação ${ }^{41}$.

A maneira como o público percebe a função, a efetividade e a eficiência do Sistema Único de Saúde é mediada pelos veículos de comunicação. Os resultados mostram que as reportagens e notícias tratam a gestão da saúde pública no Rio de Janeiro enfatizando os aspectos críticos do sistema, fazendo uso constante de imagens de 'caos' e 'emergência' quando tratam de aspectos de prestação de serviços. Vista como uma 'moldura' ou um 'quadro', a crise é construída como um fator estruturante do sistema público de saúde no Rio de Janeiro.

Esses resultados são similares àqueles encontrados por Oliveira ${ }^{48} \mathrm{em}$ estudo sobre a relação das redes de comunicação midiática e a constituição simbólica das políticas públicas de saúde. As reportagens e notícias publicadas sobre o SUS são frequentemente associadas às mazelas e à dificuldade do setor, a partir de um pressuposto de ineficiência do governo e de incompetência das autoridades ou profissionais da área, levando a uma forma de apreensão sobre o tema pouco reflexiva. Essas notícias procuram revelar mais os desvios do SUS do que as mudanças substantivas que ele pode provocar no cenário social. Dessa forma, a visibilidade pública obtida pelo SUS torna-o politicamente frágil, comprometendo sua gestão e implementação.

Resultado semelhante foi encontrado por Menezes $^{49}$, ao estudar a representação do SUS na mídia impressa em Goiânia. O SUS é apresentado como 'falido', 'mal administrado' e 'confuso'. Da mesma forma, em pesquisa sobre a construção da imagem do SUS no jornal O Globo entre 2010 e 2011, Machado ${ }^{50}$ chega à conclusão que existe uma tendência na cobertura midiática a desconstruir os avanços do SUS, evitando diálogos amplos com vários setores da sociedade. De acordo com a autora, os jornais tendem a utilizar acontecimentos negativos em qualquer ponto da cadeia de atendimento como uma característica comum do sistema de saúde, ao mesmo tempo em que omitem a referência ao sistema (e mesmo à sigla SUS) em matérias positivas.

Os relatos jornalísticos selecionam, ampliam e hierarquizam os acontecimentos para criar a imagem de um sistema de saúde em constante crise, realçando aspectos e episódios singulares (frequentemente ocorridos em uma única região ou mesmo em um único hospital). Isso revela também a pouca atenção dada aos princípios organizativos e às prioridades da política de saúde brasileira. Para a mídia, o locus da saúde pública é o hospital e a emergência é a principal porta de entrada e preocupação do sistema, ao mesmo tempo em que aspectos preventivos e de promoção da saúde são preteridos diante de uma interpretação oriunda do paradigma saúde-doença. Ao estudar a crise dos serviços de saúde no cotidiano da mídia impressa em Mato Grosso do Sul, Menegon ${ }^{46}$ chega a uma conclusão similar e afirma que "as notícias analisadas redescrevem a hegemonia do modelo hospitalocêntrico, reservando lugar periférico aos serviços de saúde que privilegiam a prevenção de doenças e a promoção da saúde (Unidades Básicas de Saúde, Programas de Saúde da Família, Centros de Referência)".

Isso pode ser explicado pela falta de acesso dos especialistas em saúde pública aos meios de comunicação de massa. O baixo volume de notícias da categoria 'crise' que consideram a razão principal a baixa cobertura da atenção básica nos municípios fluminenses está relacionada à constituição do universo midiático, que é baseado em campo de forças no qual diferentes atores sociais buscam fazer prevalecer determinados sentidos através de suas práticas discursivas, tornando-o um locus de tensão permanente. É como se fosse uma arena social em que coexistem tentativas diversas de construção, afirmação ou negação de significados ${ }^{49}$.

Nesse sentido, as interpretações e os discursos dos especialistas da área disputam com a mídia a hegemonia de sentido da 'crise' na saúde pública do Rio de Janeiro. Além disso, nesse quadro de atores em disputa, o acesso às informações geradas por esse aparato técnico-informacional se dá de forma desigual, uma vez que o próprio sistema midiático reproduz as formas assimétricas das relações sociais, principalmente 
a econômica. A mídia, hoje, está organizada em rede e grupos que concentram grandes empresas; estas monopolizam os principais jornais do estado do Rio e são responsáveis pelo foco da primazia da solução da ‘crise' baseada na suposição de que o que é privado é melhor, atendendo, assim, a grupos de interesse, em contraposição ao discurso dos especialistas que é desconsiderado.

Nos resultados, observa-se a queda no número de notícias e reportagens sobre crise quando comparamos o período de governo de Rosinha Matheus (2003-2006) e Sérgio Cabral (2007-2011). Isto pode estar relacionado ao momento político do estado e município na saúde, principalmente no que tange ao acesso aos serviços de saúde e aos financiamentos (ver Tabela 2). De fato, existe uma diferença significativa na cobertura da atenção primária no período, bem como no volume de recursos destinados para a saúde.

As mudanças encontradas nos resultados relativas às explicações mais importantes para a crise ao longo dos anos estão relacionadas com outros fatores. O governador Sérgio Cabral e o seu secretário de saúde, Sérgio Côrtes, foram os empreendedores da mudança na política de gestão em saúde e fizeram isso por meio de sucessivos enquadramentos da questão da gestão da saúde no território, primeiramente rearticulando-a como um problema de atendimento emergencial e, a seguir, como um problema da ineficiência do setor público na gestão de recursos humanos.

A hipótese apresentada inicialmente se confirma: a mídia foi o ator principal desse processo, ao fazer um enquadramento da questão da saúde no estado análoga à perspectiva do governador e do secretário estadual de saúde. As explicações cambiantes sobre os motivos da crise parecem seguir as interpretações dadas pelo governador. Entre 2006 e 2007, momento no qual se discutiam e davam início à implantação das UPA, e no qual a questão da saúde foi reinterpretada pelo governador e o seu secretário como um problema de falta de unidades emergenciais, as razões da crise aparecem nos jornais de maior circulação do estado como ligadas eminentemente à falta de recursos físicos, ou seja, de leitos e emergências.

Naquele período, acentua-se a prática discursiva de extrapolar a situação de dificuldades operativas em algumas unidades de saúde, especialmente nos hospitais gerais sob gestão estadual como um problema crítico do sistema de saúde fluminense. Podemos ver que no mesmo período aumentam as reportagens e notícias sobre problemas em unidades de saúde particulares. Por outro lado, justamente no mesmo período somem da cobertura as interpretações alternativas sobre a crise, notadamente aquelas ligadas à baixa cobertura da atenção básica no território fluminense.

Seguindo essa lógica, seria de se esperar um aumento significativo das notícias relacionando a situação crítica à falta de recursos humanos em 2011. Todavia, apesar de ter aumentado em 2009, à primeira vista os veículos de comunicação não parecem engajados nessa explicação. Na verdade, a questão dos recursos humanos em saúde aparece em 2011 ligada ao amotinamento do Corpo de Bombeiros Militar do Estado do Rio de Janeiro, e por isso não entra no clipping de notícias realizado pela RADIS.

Aquestão da falta de recursos humanos em saúdeé tratada como uma das consequências do amotinamento e não como um problema em si. A falta de médicos não entra na categoria 'crise' do sistema de saúde, ela aparece alternativamente como função de um problema com os bombeiros e como explicação para a solução apresentada pelo governador, as Organizações Sociais de Saúde. Como vimos nos resultados, as OSs são sempre tratadas sob uma ótica positiva, apresentando a gestão privada como solução para diversas questões do sistema de saúde.

Este estudo apresenta algumas limitações, principalmente no que tange às suas fontes de dados, que são provenientes da base de dados do Programa RADIS de Comunicação e Saúde, ou seja, não foram coletados dados primários nos veículos de comunicação utilizados. Isso pode ter criado viés nas reportagens e notícias coletadas. Por este motivo, é importante realização de estudos subsequentes que trabalhem com coleta de dados primários para confirmar a hipótese apresentada neste artigo. 


\section{Conclusão}

Este artigo teve como objetivo analisar o papel dos meios de comunicação de massa na formulação da agenda governamental de saúde no Rio de Janeiro. A análise dos dados mostrou que a maneira como a mídia retratou o SUS teve um papel importante na entrada do tema da gestão dos serviços de saúde no território fluminense. Ao verificarmos a ocorrência de notícias da categoria 'crise', chamam atenção dois aspectos: o primeiro é a pouca utilização de explicações ligadas à corrupção para explicar a suposta crise da gestão da saúde; o segundo é o pouco volume de notícias dentro da categoria 'crise' que consideram como razão principal a baixa cobertura da atenção básica nos municípios fluminenses, uma vez que há consenso sobre essa questão entre os especialistas.

Com isso, o enquadramento da crise é construído pela mídia como caos, emergência e fator estruturante do sistema de saúde do Rio de Janeiro. O foco da crise também é percebido no ambiente hospitalar, reforçando mais uma vez a falta de acesso dos especialistas aos meios de comunicação de massa. Isso demonstra também que o universo midiático é um locus de tensão permanente, um campo de disputa entre diversos atores sociais que buscam e constroem significados. Dessa forma, é a palavra 'crise' que está em disputa.

A mídia, nesse caso, foi o principal ator na mudança de percepção com relação à mudança de gestão, ou seja, por meio de processos de interpretação do que ocorreu, salientou determinados aspectos, tornando-os visíveis para o público e conferindo-lhes sentidos.

\section{Referência}

1. Paim JS, Travassos C, Almeida C, Bahia L, Macinko J. The Brazilian health system: history, advances and challenges. Lancet. 2011;377(9779):1778-97.

2. Gerschman SV. Políticas comparadas de saúde suplementar no contexto de sistemas públicos de saúde: União Europeia e Brasil. Ci Saúde Coletiva. 2008;13(5):1127-37.

3. Bahia L, Scheffer M. Planos e seguros privados de saúde. In: Giovanela L, Escorel S, Lobato LVC, Noronha JC, Carvalho AI, organizadores. Políticas e sistemas de saúde no Brasil. Rio de Janeiro: Editora Fiocruz; 2012. p. 429-456.

4. Rio de Janeiro (Estado). Lei $n^{\circ} 2.528$, de 19 de outubro 2011. Dispõe sobre a qualificação de entidades sem fins lucrativos como organizações sociais, no âmbito da saúde, mediante contrato de gestão, e dá outras providências [Internet]. 20 out. 1999 [citado 2018 ago. 29]. Disponível em: http://alerjln1.alerj. rj.gov.br/CONTLEI.NSF/b24a2da5a077847c032564f4005d4bf2/c8d2df9a2566fd0e83257911005f4c7a?Op enDocument

5. Instituto Brasileiro de Geografia e Estatística (IBGE). Pesquisa de Assistência Médico Sanitária. Rio de Janeiro; [2010?] [citado em 2018 ago 29]. Disponível em: https://www.ibge.gov.br/estatisticasnovoportal/sociais/saude/9067-pesquisa-de-assistencia-medico-sanitaria.html?=\&t=0-que-e

6. Soranz D, Pinto LF, Penna GO. Eixos e a Reforma dos Cuidados em Atenção Primária em Saúde (RCAPS) na cidade do Rio de Janeiro, Brasil. Ci Saúde Coletiva. 2016;21(5):1327-1338.

7. Dourado I, Medina MG, Aquino R. The effect of the Family Health Strategy on usual source of care in Brazil: data from the 2013 National Health Survey (PNS 2013). Int J Equity Health. 2016 Nov $17 ; 15(1): 151$.

8. Cowling TE, Harris M, Watt H, Soljak M, Richards E, Gunning E et al. Access to primary care and the route of emergency admission to hospital: retrospective analysis of national hospital administrative data. BMJ Qual Saf. 2016;25:(6):432-40.

9. Acosta AM, Silva Lima MA. Características de usuários frequentes de serviços de urgência: revisão integrativa. R Eletr Enferm. 2013;15(2):564-73.

10. Tang N, Stein J, Hsia RY, Maselli JH, Gonzales R. Trends and characteristics of US emergency department visits, 1997-2007. JAMA 2010;304(6):664-70.

11. Machado CV. Novos modelos de gerência nos hospitais públicos: as experiências recentes. Physis. 2001;11(1):105-97. 
12. Presidência da República (BR). Casa Civil. Subchefia de Assuntos Jurídicos. Decreto no 5.392, de 10 de março de 2005. Declara estado de calamidade pública no setor hospitalar do Sistema Único de Saúde no Município do Rio de Janeiro, e dá outras providências. DOU [Internet]. 2005 [citado em 2018 ago. 22]. Disponível em: https://goo.gl/LW8Lpq

13. Gershman SV. Política e gestão da saúde no governo do estado do Rio de Janeiro. In: Gerscman, SV; Santos, MA, organizadores. Saúde e políticas sociais no Rio de Janeiro. Rio de Janeiro: Editora Fiocruz; 2016.

14. Scheufele DA, Tewksbury D. Framing, agenda setting, and priming: The evolution of three media effects models. J Commun. 2007:57(1):9-20.

15. Kingdon JW. Agenda, alternatives and public policies. 2nd Ed. Essex: Pearson, 2014.

16. Arts B, Tatenhove JV. Policy and power: a conceptual framework between the 'old' and 'new' policy idioms. Policy Sci. 2004;37(3):339-56.

17. Majone G. Evidence, argument and persuasion in the policy process. New Haven: Yale University Press; 1989.

18. Goffman E. Frame analysis: an essay on the organization of experience. Cambridge: Harvard University Press; 1974.

19. Kahneman D, Tversky A. Choices, values, and frames. Am Psychol. 1984;39(4):341-50.

20. Lakoff G. Don't think of an elephant. White River Junction: Chelsea Green Publishing; 2004.

21. Entman RM. Symposium framing US coverage of international news: contrasts in narratives of the KAL and Iran air incidents. J Commun. 1991;41(4):6-27.

22. Iyengar S. Is anyone responsible?: how television frames political issues. Chicago: University of Chicago Press; 1994.

23. Porto M. Enquadramentos da mídia e política. Comunicação e política: conceitos e abordagens. São Paulo: Unesp; 2004.

24. Campos LA, Feres Jr J, Daflon VT. Managing the public debate: O Globo newspaper and the affirmative action controversy. R Bras Ci Pol. 2013;11:7-31.

25. Gamson W. Talking politics. New York: Cambridge University Press; 1995.

26. Knaggard A. Framing the problem: knowledge-brokers in the multiple-streams framework. In: Zohlnhöfer R, Rüb Fw, editors. Decision-making under ambiguity and time constraints assessing the multiple-streams framework. Colchester: ECPR; 2016.

27. Schön DA; Rein M. Frame reflection: toward the resolution of in- tractable policy controversies, New York: BasicBooks; 1994.

28. Jasanoff S; Wynne B. Science and decision-making. In: Rayner, S; Malone, EL, editors. Human Choice and Climate Change. Vol. 1, The societal framework. Columbus, OH: Battelle Press; 1998. p. 1-87.

29. Zahariadis N. Ambiguity and choice in public policy: political decision making in modern democracies. Washington, DC: Georgetown University Press; 2003.

30. Cohen BC. Press and foreign policy. New Jersey: Princeton university press; 2015.

31. McCombs M, Shaw DL. The agenda-setting function of mass media. Public Opin Quart. 1972; 36(2):176-87.

32. Williams Jr W, Shapiro M, Cutbirth C. The impact of campaign agendas on perceptions of issues. In: Protess, D, McCombs, M., editors. Agenda setting: readings on media, public opinion, and policymaking. Hillsdale: Lawrence Erlbaum, 1991. p. 251-259.

33. Dearing JW, Rogers, EM. Agenda-setting. Thousand Oaks, CA: Sage; 1996.

34. Tuchman G. Making news: a study in the construction of reality. New York: The Free Press; 1978.

35. Gitlin T. Mídias sem limite: como a torrente de imagens e sons domina nossa vida. São Paulo: Record; 2003.

36. Entman RM. Framing: Toward clarification of a fractured paradigm. In: Levy M; Gurevitch M., editors. Defining media studies. New York: Oxford University Press; 1994. p. 293-300.

37. Howlett M. A dialética da opinião pública: efeitos recíprocos da política pública e da opinião pública em sociedades democráticas contemporâneas. Opin Públ. 2000;6(2):167-86. 
38. Gibson R. Out of control and beyond understanding: acid rain as a political dilemma. In: Paehlke R, Torgerson D, organizers. Environmental politics and the administrative state. Peterborough: Broadview Press; 1990. p. 243-282.

39. Cook FL, Tyler TR, Goetz EG, Gordon MT, Protess D, Leff DR, Molotch HL. Media and agenda setting: effects on the public, interest group leaders, policy makers, and policy. Public Opin Q. 1983 Spring;47(1):16-35.

40. Hall A. Reading realism: audiences' evaluations of the reality of media texts. J Commun. 2003; 53(4):624-41.

41. Félix CA. Limites do enquadramento: desafios metodológicos para a análise da mídia impressa. In: Lerner K, organizadora. Saúde e jornalismo: interfaces contemporâneas. Rio de Janeiro: Editora Fiocruz; 2014.

42. Manin B. The principles of representative government. New York: Cambridge University Press; 2002.

43. McCombs M. A Teoria da agenda. São Paulo: Vozes; 2009.

44. Cirino JÁ, Tuzzo AS. Comunicação e saúde: mídia como agente social de saúde. In: Anais do 170 Congresso de Ciências da Comunicação na Região Centro-Oeste; 2015 jun. 4-6; Campo Grande. São Paulo: Intercom; 2015.

45. Oliveira VC. Os sentidos da saúde nas mídias jornalísticas impressas. Reciis [Internet]. 2013 fev. [citado em 2018 ago. 22];6(4). Disponível em: https://goo.gl/x3yD2q

46. Menegon VS. Crise dos serviços de saúde no cotidiano da mídia impressa. Psicol Socied. 2008;20(ed esp):32-40.

47. Zaller J. The nature and origins of mass opinion. New York: Cambridge University Press; 1992.

48. Oliveira VC. A comunicação midiática e o Sistema Único de Saúde. Interface 2000;4(7):71-80.

49. Menezes KA. A representação do SUS na mídia. In: Claudomilson F, Cirina JA. Representações sociais e comunicação: diálogos em construção. Goiânia: UFG/FIC/PPGCOM, 2015. p. 152-178.

50. Machado, IB. Percepções sobre o SUS: o que a mídia mostra e o revelado em pesquisa. In: Lerner K, organizadora. Saúde e jornalismo: interfaces contemporâneas. Rio de Janeiro: Editora Fiocruz; 2014. p. 235-250. 